\title{
The theorist
}

\author{
Francis Crick: Discoverer of the \\ Genetic Code \\ by Matt Ridley \\ HarperCollins: 2006.213 pp. $€ 12.95, \$ 19.95$
}

\section{Horace Freeland Judson}

Any biographer of Francis Crick faces a difficult problem: he was the greatest biologist of the latter half of the twentieth century, yet his life was curiously one-dimensional. It was intensely concentrated but narrowly focused. By far the most important part of his life was his science, and because of his pre-eminence and unique role, his life was the life of his science in his day. And what a day it was - the golden age of molecular biology.

A biography will therefore be shaped by strategic choices: how far to go in addressing the other dominant aspects of Crick's life and personality - his vivid sexuality and his obdurate atheism - and, more importantly, at what level of detail to treat the science. Crick was erotically hyperactive and successful, although not predatory as far as I know. Matt Ridley does write of this, lightly and tactfully - an acknowledgement rather than an examination. That's fine. The atheism was rooted and militant. Ridleyintroduces it where it determined Crick's choice of problems: molecular biology in the late 1940s to dispel the last traces of vitalism, neurobiology in the 1970 s to demystify consciousness. All well and good. But I came away from the book regretting that Ridley did not engage Crick's science and his intellectual style more closely, because here lies the richness of Crick's life.

As Crick's first biographer, Ridley has missed a unique opportunity. He could have been definitive, pre-empting later biographers. This book is one of a series, under the rubric 'Eminent Lives', intended to be short, snappy pairings of top people with strong writers. Ridley is an established science journalist who writes a pleasant, ambling prose. But he has not reached to the well-springs of Crick's singular role.

The subtitle is symptomatic, for Crick was both less and far more than "discoverer of the genetic code". Breaking the code was a paradigmatic example of collective-competitive effort. The idea that there must be a code had been put forward in 1944 by the physicist Erwin Schrödinger. From the moment in the spring of 1953 when Crick and James Watson announced the structure of DNA, the need to determine how the structure carries the code was obvious. That summer, the eccentric physicist George Gamow was the first to propose an actual mechanism, wildly wrong but forcing the question. The task itself - to identify which of the 64 triplet codons of the four bases in DNA specify which of 20-odd amino acids - took several years and at least half a dozen scient ists and laboratories to solve. Crick himself did very little of the laboratory work. Rather, he was the explicator, the arbiter, the taskmaster.

Crick was above all the theorist - and that's the unifying thread. Not just with the coding problem but throughout his career, Crick was the one who put other scientists' thoughts in order. He soaked up data, mostly other people's, but saw beyond the data to their meaning, their shape, their implications. He found principles, and did it with a preternatural clarity of mind and in inimitable style.
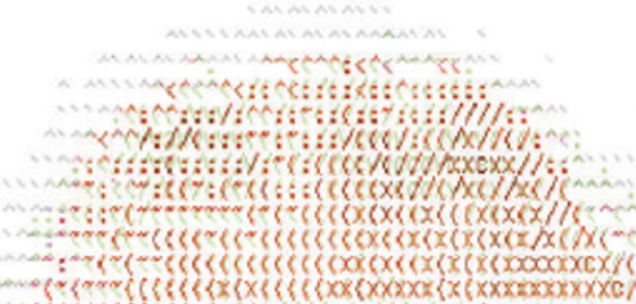

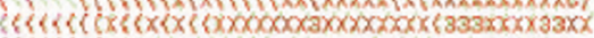

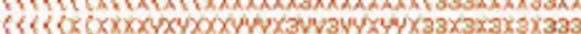

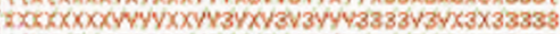

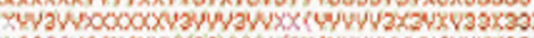

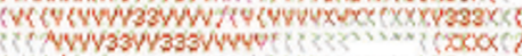

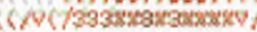

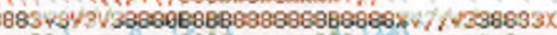

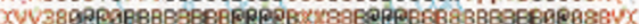
(1) xuw

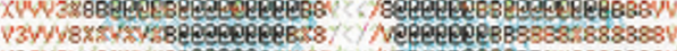

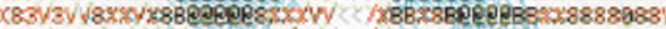

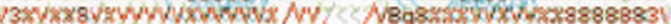

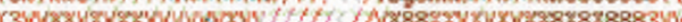

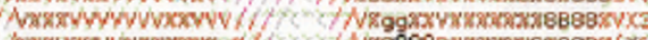

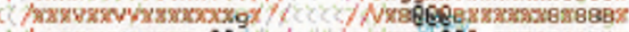

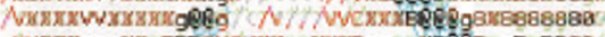

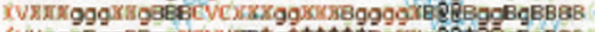

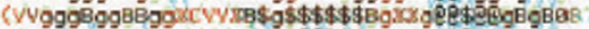

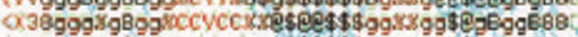

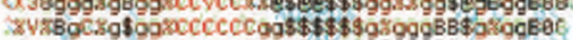

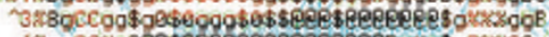
〈

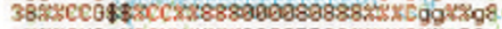

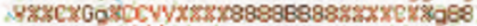

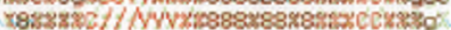

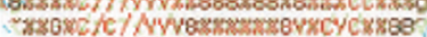

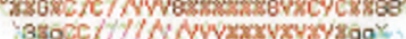

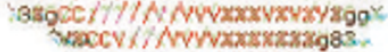

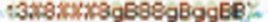

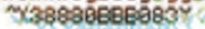

In the interplay with Watson that led to the structure of DNA, it is clear that while Watson had the immediate visual insights, Crick framed their approach in general terms. Ridley, by necessity, tells the old familiar story of the discovery, but he fails to capture the nature of the intellectual interaction - or the psychological dimension, which was driven by Watson's intense admiration of Crick's prowling, relentless intelligence and by his envy of Crick's success with girls.

Ridley also fails to reach the origins of the historic conflict between the other scientists working for the structure, Rosalind Franklin and Maurice Wilkins at King's College London. Wilkins had been getting important new $\mathrm{X}$-ray-diffraction patterns from DNA. Franklin, an X-ray crystallographer, was recruited in the spring of 1950 (not in December, as Ridley writes). She joined the lab in January 1951, and Ridley makes no mention of a meeting she had then with the physicist Alexander Stokes and a graduate student, Raymond Gosling, at which John Randall, the lab's director, gave her a supply of the best DNA they had and appointed Gosling her assistant. Crucially, Wilkins was away on vacation. Franklin had every reason to think the DNA was exclusively hers. When Wilkins returned and expected to collaborate with her, she shut him out. He grumbled about her to Crick and Watson, and in February 1953 he notoriously showed Watson an X-ray diagram she had obtained - which they interpreted as she had failed to do.

Crick's boldest, most enduring exercise in theory came in a remarkable paper, "On protein synthesis", that he read at a meeting in September 1957. It culminated in what he called the 'central dogma' of molecular biology: "Once

'information' has passed into protein it cannot get out again." Information here meant " the precise determination of sequence", either of bases in nucleic acids or of amino acids in proteins. This was a characteristically practical assertion. At a time when so much was still to be learned, it ruled out great swaths of speculation. Yet it has great philosophical force, for it is a radical statement of the physiological reason why the inheritance of acquired traits cannot occur.

The paper forever altered the fundamental logic of biology. And it epitomizes Crick's essential intellectual style. Throughout the book, Ridley's account, despite ticking off the wide range of Crick's scientific interests and accomplishments, seems to convey only fuzzily the scope, the rigour, and beyond that the clarity and energy that Crick displayed - the basis, after all, of his dominance of the field.

In 1976, Crick moved from Cambridge to the Salk Institute in La Jolla, California — and from molecular biology to neurobiology, in particular the neural, cellular basis of consciousness. He winnowed the literature, then with new colleagues put forth a succession of ideas and strictures. As he himself recognized, he did not get far. Yet, as Ridley writes, Crick's interest, his unflagging skill at incisive generalization, and his reputation made the physiology of consciousness respectable. His style persisted.

Ridley's book is marred by factual errors, which perhaps ought to be beneath the attention of a brief review, yet they occur in such a swarm that they sap the reader's confidence. For example, the first experimental sighting of what came to be recognized as messenger RNA was made not by two Russian scientists, as Ridley writes, but by Elliot Volkin and Lazarus Astrachan, both American born, who worked at the Oak Ridge National Laboratory in Tennessee. Again, writing of the French molecular biologist Jacques Monod, Ridley lists his 
remarkable qualities: sailor, cellist, and so on, and includes "communist", without explanation. This is a reprehensible distortion. Monod joined the French communist party during the war for just one reason, he told me: it was the only way he could have any influence on the strategy and tactics of the armed resistance, in which he then rose to chief of operations for all of France. After the war he quietly dropped out, until in 1948 he publicly denounced the fraudulent claims of Stalin's geneticist and science chief, Trofim Lysenko - and with terrific effect.

Horace Freeland Jud son is at 807 West

University Parkway, Baltimore,

Maryland 21210, USA.

\section{Coping with uncertainty}

\section{From Cosmosto Chaos: The Science of Unpredictability \\ by Peter Coles \\ Oxford University Press: 2006. 224 pp. \\ $£ 25, \$ 44.50$}

\section{Gianpietro Malescio}

If the process through which civilization evolved were condensed into a few words, these could be: posing questions, finding answers. As those with children know well, wondering about the world is intrinsic to human nature. This attitude is generally lost as we grow up (life is a tough business), but a good scientist retains it as an adult. In principle, finding answers is the ultimate goal of a scientist. However, scientific answers have a peculiar character: they do not represent absolute truth acquired once and for all, but only temporary beliefs subject to continuous, critical revision. Scientific knowledge is anti-dogmatic: it represents the most reliable conclusion that can be drawn on the basis of the available data. There are no certainties in the realm of science. This may seem profoundly disappointing to the general public, but it should not. Science is a way of thinking much more than it is a body of knowledge. Its true achievement is not providing answers, but rather a method through which answers can be sought.

A basic instrument of this method is represented by probability theory. As Peter Coles brilliantly illustrates in his engaging new book, From Cosmos to Chaos, probability theory makes it possible to extract meaningful information from a sea of noisy data, to deal with intrinsically probabilistic processes, and to infer conclusions on the basis of incomplete information.

After explaining the basics of probability theory, Coles offers a ride across virtually the entire spectrum of the physical sciences, including thermodynamics, cosmology, chaos theory and quantum mechanics, as well as stimulating issues such as the anthropic principle and life on other worlds. Each topic is considered from the specific perspective of how it involves, and is related to, the concept of probability. Coles also examines the impact of probability on many aspects of everydaylife. He shows us how the decisions of law courts and medical tests, as well as more mundane activities such as gambling strategies, may suffer deeply from an incorrect use of statistics. To illustrate how probability theory works, Coles presents some intriguing and often surprising examples, encouraging readers to think for themselves and providing them with material to entertain and amaze their friends. I particularly appreciated the historical notes and lively anecdotes that highlight the famous and less well-known personalities who contributed to the development of the statistical of the bayesian approach. Pragmatically, the two interpretations should be considered as complementary, rather than competing. Undoubtedly, bayesian inference has profound implications as it concerns critical thinking and may lead to a deeper understanding of the scientific method. However, the ability to develop a new hypothesis or theory relies in the end on scientists' creativity, something that can hardly be delimited within a methodological framework.

I have a minor observation. Randomness, which is intrinsically related to probability, deserves a more detailed discussion than is given here. In particular, the Monte Carlo method is mentioned only briefly, despite its importance and wide use in virtually every branch of science.

Altogether, the book provides a truly enjoyable overview of the role of probability in science, as well as in everyday life. It is aimed essentially at non-specialist readers, but even those who are familiar with its contents will enjoy the stimulating presentation. Finally,

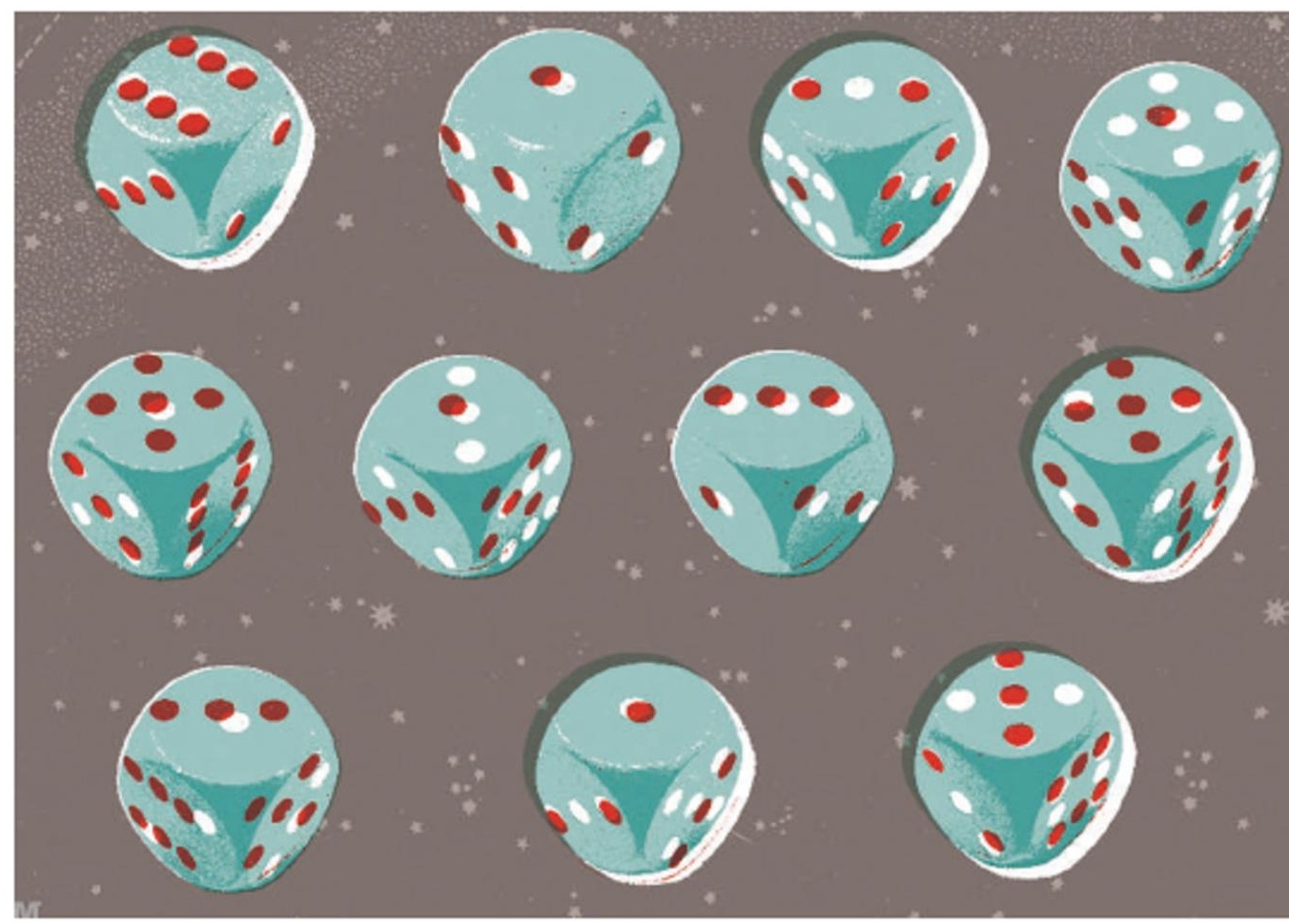

approach to science. Coles points out that most of these were astronomers. Historically, men of science generally applied their talents to a range of disciplines, so most of the people cited in the book might also be considered as mathematicians and physicists.

A central chapter of the book is devoted to the controversy between the frequentist and the bayesian interpretations of probability. The former interprets probability as a frequency of occurrence in repeated experiments, whereas in the latter probability measures the degree of belief an individual has in an uncertain proposition. As Coles openly declares, one of the book's objectives is to argue in favour
I fully endorse Coles' passionate plea at the end of the book for a better integration of science and society. To face challenges such as large-scale pollution, the energy crisis or food shortages, we will need all the instruments that science puts at our disposal. Perhaps an even greater threat is represented by fundamentalisms of any kind (religious, political, economical) that aim to impose their dogmas on the whole of society. Science, or rather, the forma mentis it gives us, may offer the best antidote for defying them.

Gianpietro Malescio is in the Department of

Physics, University of Messina,

98166 Messina, Italy. 